\title{
ESTHETIC MANAGEMENT OF GINGIVAL HYPERPIGMENTATION USING LASER AND SCALPEL TECHNIQUE - CASE SERIES
}

Dr. Sathish Kumar K, Dr. Dhivya R, *Dr. Ramakrishnan T, Dr. Priyadurga K, Dr. M.A. Mejalla Dept. of Periodontology, Adhiparasakthi Dental College and Hospital, Melmaruvathur, Tamil Nadu, India.

*Principal, Faculty of Dentistry, Meenakshi Academy of Higher Education and Research, Maduravoyal, Chennai, Tamilnadu, India.

\section{To access $\&$ cite this article}

Website: jidam.idamadras.com

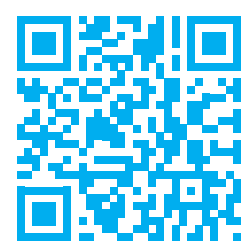

DOI:10.37841/jidam_2020_V7_I4_05

\section{Address for Correspondence:}

Dr.K. Sathish Kumar, MDS., 1674/D, opposite Gov. ITI,

Vengikkal, Thiruvannamalai-606 604.

Mail id: sathishperio94@gmail.com

\section{ABSTRACT}

The complaint of darkly pigmented gums is common particularly in patients having a very high smile line and possess esthetic problems for them. The degree of gingival pigmentation depends on melanoblast activity. Various treatment options are in practice for depigmentation which include scalpel gingivectomy, free gingival graft surgery, use of chemicals, such as $90 \%$ phenol and $95 \%$ alcohol, bur abrasion, electrosurgery, cryosurgery, and lasers. Among the various techniques, lasers offer a promising therapeutic option since it is simple, painless, and predictable. The laser has been recognized as the most effective and reliable technique having many advantages as compared to other conventional treatment modalities. It provides a bloodless and painless surgery.

KEYWORDS: Scalpel, LASER, depigmentation, esthetics.
Received
:09.06.20
Accepted
$: 31.10 .20$
Published
$: 27.12 .20$ 


\section{INTRODUCTION:}

The word aesthetic denotes beauty as opposed to the merely pleasing, indicating that the most desirable attributes are present. Achieving optimal oral beauty involves many factors, one of which is gingival appearance. Harmony of a smile is based on not only the color of teeth but also depends on the color of gingival tissues. The objective of gingival esthetics is to keep healthy good looking gingival form around teeth that must be restored. A smile also has additional day-to-day benefits. When you have a healthy smile, you are always keen to show it off in society. It makes us feel more confident when we communicate with others, and it also affects how people around us view us ${ }^{1}$. It leads to the release of endorphins that make you feel happier. That eases the day-to-day stress that you deal with. A healthy smile can improve the health of not only our mouth but our body too. It could be an aesthetic problem for some patients, particularly when it is located in the anterior labial gingiva, which is associated with a high smile line and is uneven in appearance. Gingival depigmentation can be done by scraping ${ }^{2}$, free gingival autografting ${ }^{3}$, cryosurgery ${ }^{4}$, electrosurgery ${ }^{5}$, and various types of lasers ${ }^{6}$.

\section{CASE REPORT:}

CASE 1: A 25-year-old male patient with the chief complaint of black gums reported to the Department of Periodontics, Adhiparasakthi Dental College and Hospital and he also request for the esthetic treatment of black gums. On clinical examination, his DOPI score was 3(Heavy clinical pigmentation). Treatment plan was explained to the patient and written informed consent was obtained. The patient and the staff were protected from the laser by wearing manufacturer's spectacles. For sites treated with laser, 20\% benzocaine as topical anaesthesia in the form of gel was applied for 3 minutes in maxillary anterior region, diode laser in contact mode was used. The laser ablation was done using a handpiece with fiber optic filament, $320 \mu \mathrm{m}$ in diameter set at $0.8 \mathrm{~W}$. The procedure was performed in a contact mode in apico-cervical direction on all pigmented areas. No pain or bleeding complications were observed during and after the procedure.

CASE 2: A 27-year-old male patient with the chief complaint of black gums reported to the Department of Periodontics, Adhiparasakthi Dental College and Hospital and he also request for the esthetic treatment of black gums. On clinical examination, his DOPI score was 3(Heavy pigmentation). Treatment plan was explained to patient and written informed consent was obtained. Lignocaine hydrochloride $2 \%$ with 1:100000 adrenaline was administered by the infiltration technique in the maxillary anterior region. After 5 minutes, partial dissection and peeling of the affected area were performed using BP Blade no.15c. The surgical site was irrigated often with normal saline while performing the procedure and a wet gauze pressure pack was given to control bleeding.

\section{POST-OPERATIVE INSTRUCTIONS:}

Post-operatively patient is advised to take Cap. Amoxicillin -500 mg thrice a day and analgesic Acenac-P twice a day for 3 days was prescribed to prevent post-operative pain and infection. Following the procedure, the periodontal pack was given, the patient was advised to stop brushing in that area for the next 10 days and the patient also advised to rinse the mouth with chlorhexidine mouthwash.

\section{POST-OPERATIVE EVALUATION:}

Both the patient was apparently normal immediately after the surgery. Both the patient was called on the 3rd day when the progressive healing of the surgical site was seen. The patient did not report any pain or discomfort on the side treated with the laser after the procedure. He felt little discomfort on the side treated with the scalpel but there was no pain on that side. At a 1-week review appointment, complete healing of wound on both sides was seen. At present, i.e. after 6 months, the pigmentation has recurred in some solitary areas. The patient is still on follow-up visits. 


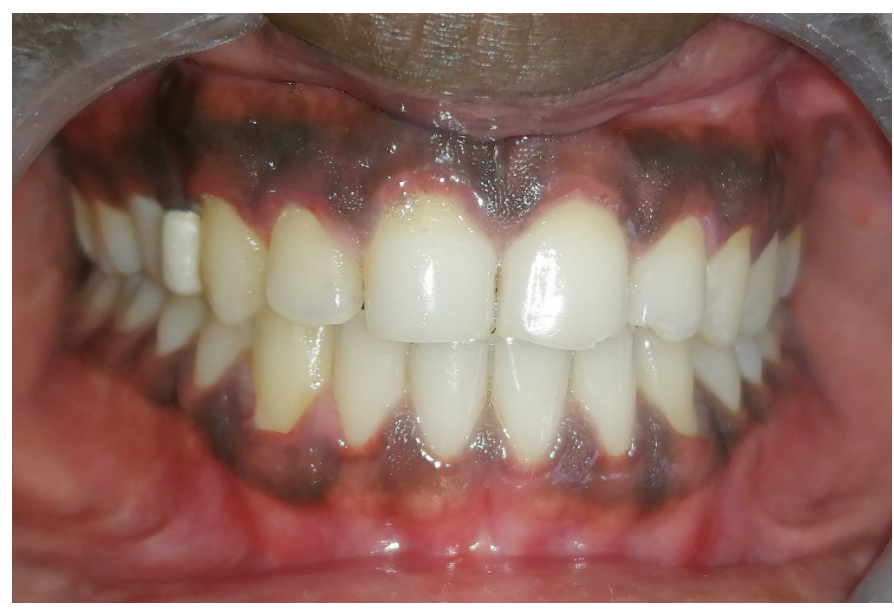

Fig 1: Pre Operative Image (Case 1)

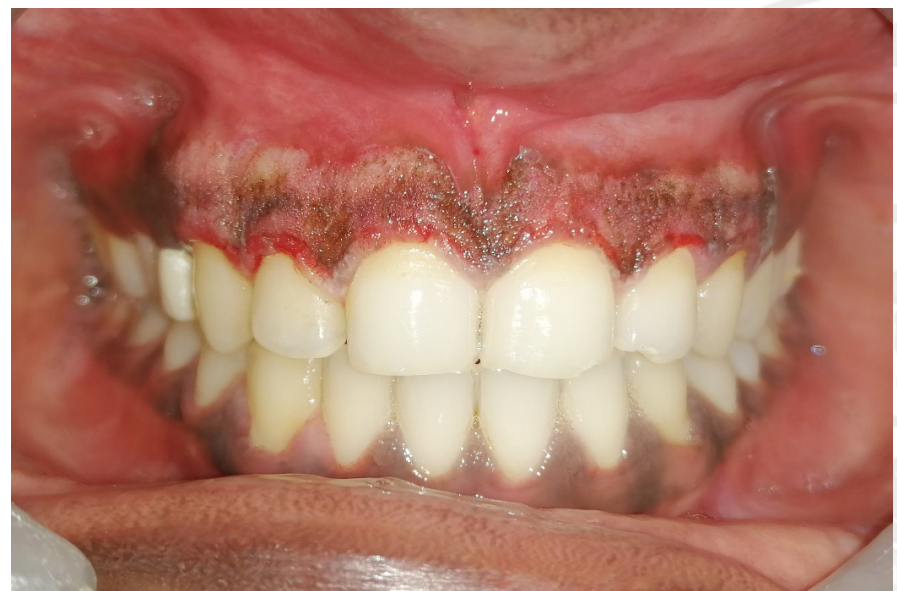

Fig 2: Immediate Post Operative Image - Laser Depigmentation

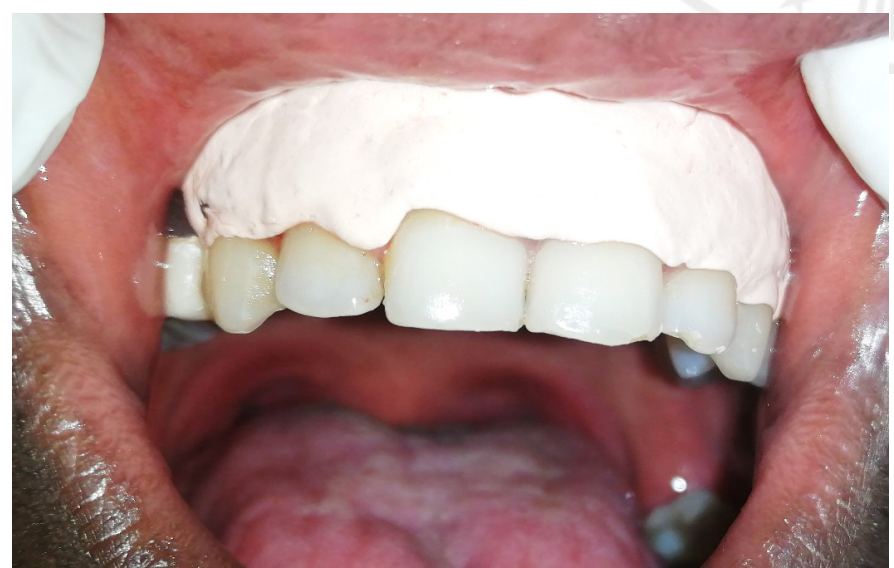

Fig 3: Periodontal Dressing Given

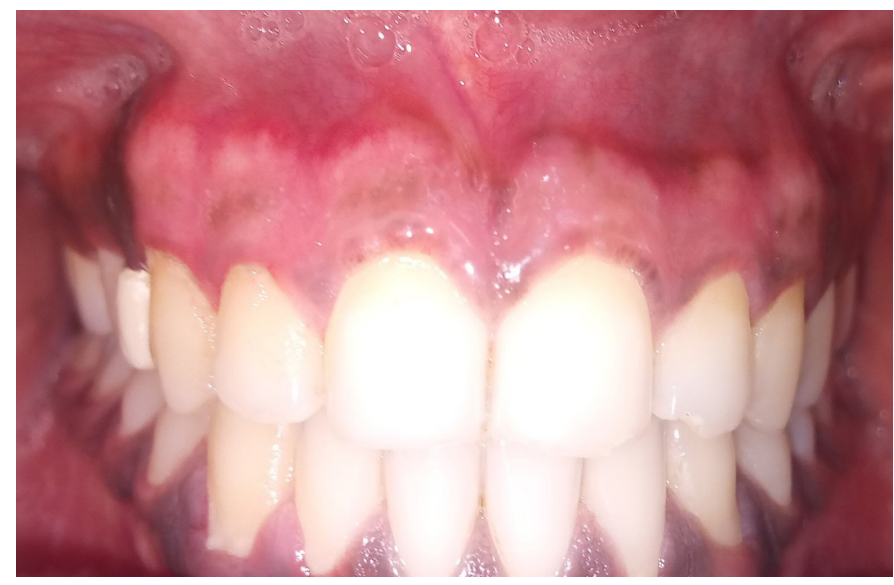

Fig 4: 3 Month Post Operative Image - Laser Depigmentation

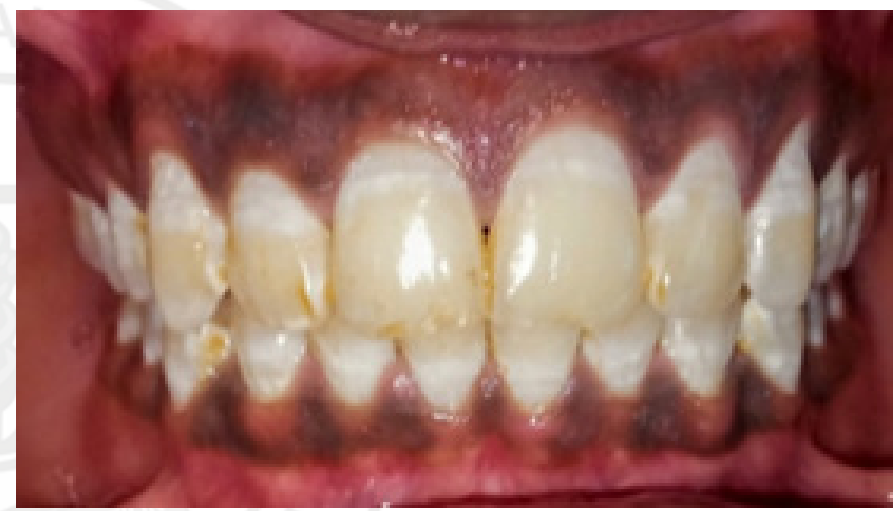

Fig 5: Pre Operative Image (Case 2)

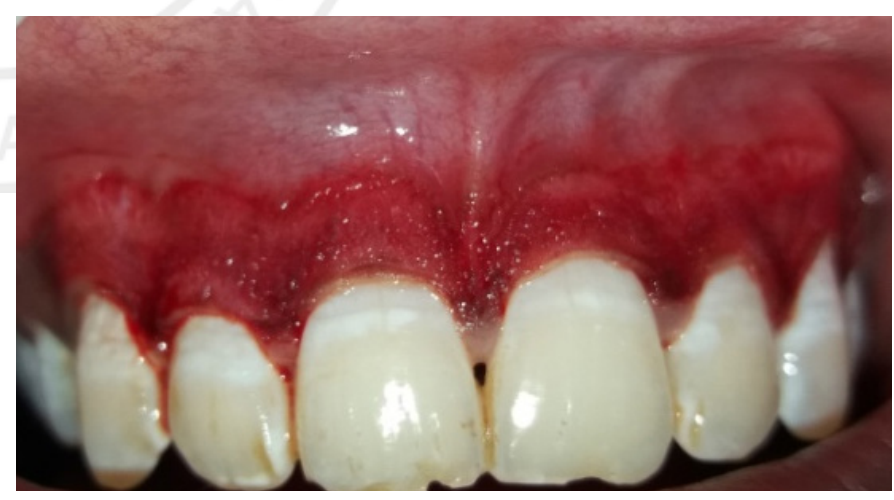

Fig 6: Immediate Post Operative Image - Scalpel Depigmentation 


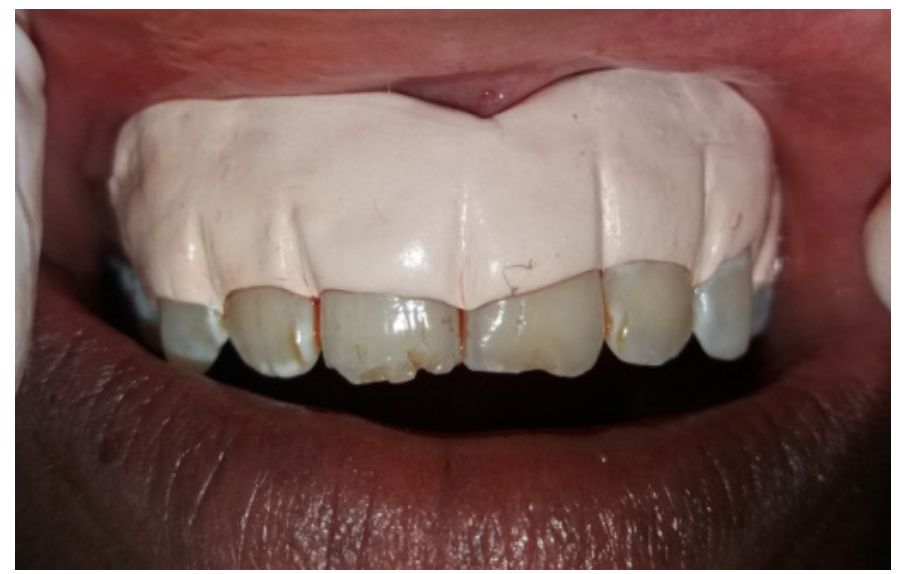

Fig 7: Periodontal Dressing Given

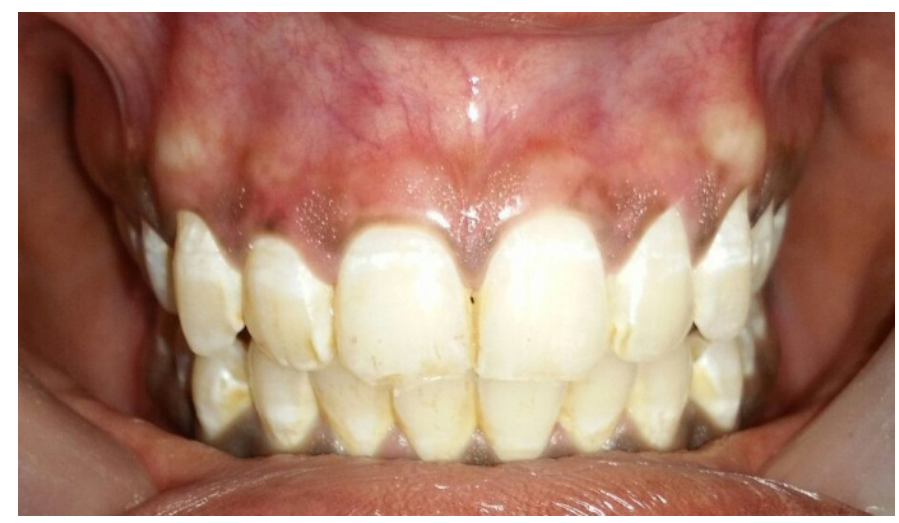

Fig 8: 3 Month Post Operative Image - Scalpel Depigmentation

\section{TABLE 1 : Methods For Gingival Depigmentation}

1. Gingival abrasion technique

2. Scalpel surgical technique.

3. Cryosurgery

4. Electro surgery

5. Lasers

6. Neodymium;Aluminum-Yitrium-Garnet (Nd- YAG) lasers. Erbium-YAG lasers.

7. Carbon-di-oxide CO21aser

8. Chemical method

Methods aimed at masking the pigmented gingiva with grafts from less pigmented areas:

1. Free gingival grafts

2. Acellular dermal matrix allograft 


\section{DISCUSSION:}

The color of the healthy gingiva may vary from pale pink to a deep purplish hue, which depends on the vascularity of gingiva, thickness of epithelium, degree of keratinization of epithelium and the intensity of melanogenesis. A variation in gingival pigmentation is genetically determined in their pigment-producing capacity.

The gingiva is the most commonly affected intraoral tissue, which is responsible for an unaesthetic appearance. Since the color of the gingiva can vary, the homogeneity of color is more important. Excess deposits of melanin can cause dark patches on the gingiva this form is known as gingival hyperpigmentation, particularly at the base of the interdental papillae. The gingiva is the commonly affected tissue, which is responsible for an unpleasant appearance in the oral cavity. Melanin hyperpigmentation often occurs in the gingiva as a result of an abnormal deposition of melanin. This can be caused by a wide range of local and systemic factors. Some of the local factors are amalgam tattoo, Pigmented Nevi, Oral melanotic macules, Melanoma etc., Gingival depigmentation is a procedure used in periodontal surgery to remove these discolorations. The first and foremost indication for depigmentation is patient demand for improved esthetics.

Scalpel technique involves surgical removal of gingival epithelium along with a layer of the underlying connective tissue which allows the denuded connective tissue to heal by secondary intention. Delicate scarring, exposure of the alveolar bone at areas where the gingiva is thin may occur occasionally and repigmentation are the few disadvantages of the procedure.

In the case of laser depigmentation, the ability of Melanocytes to absorb the laser is depend on the laser wavelength, and its ability to penetrate tissue. Melanocytes has an absorption spectrum range from 351 to $1064 \mathrm{~nm}$. The laser beam has the ability to destroy the epithelial cells including those at the basal layer, and hence reduces the repigmentation. Results of both treatment modalities were stable to some extent with slight recurrence seen as solitary units of pigments mainly in the papillary area in both sites at 3 and 6 months
There are many advantages of lasers over surgical procedures. According to Wigdor et al $(1995)^{7}$, these include:

1. Minimize bleeding(high energy beam photocoagulation),

2. Reduce bacterial infections(sterilizes the area being worked on),

3. Reduce anxiety in patients,

4. Minimize postoperative swelling and scarring,

5. Painless procedure does not require anesthesia

All these above-mentioned advantages are achieved in the above case. During the procedure, there was no bleeding, which is always associated with other surgical approaches like gingival abrasion technique, scalpel technique, free gingival autografting, or gingivectomy are used. Also no postoperative pain was experienced by the patient and no swelling or any other signs of infection were noticed, whereas other alternative procedures have to be accompanied by the administration of antibiotics and analgesics to minimize postoperative infection and pain.

\section{DISADVANTAGES OF LASER,}

1. Most expensive since the cost of the laser is much higher,

2. Laser is very delicate to handle

3. Need for Personal protective equipment

4. It is harmful to human beings (hazards for the direct vision of the beam)

Perlmutter et al. in 1986 conducted a study the results showed that gingival surgical procedures performed solely for cosmetic reasons offer no permanent results ${ }^{8}$. The spontaneous repigmentation is due to melanocytes from the normal tissue multiply and transfer into the depigmented areas.

\section{CONCLUSION:}

In conclusion, number of techniques are available with some advantages and disadvantages. However, choice of the technique is depend on individual appearance, clinical expertise and patient affordability. The present cases revealed that both the scalpel and diode laser technique used for gingival depigmentation results in similar outcomes. Recently, the laser depigmentation technique has been accepted as the most effective, painless and reliable technique. The technique used here produced preferred results, 
and above all, the patients were pleased with the outcome, which is the ultimate goal that is carried out.

FINANCIAL SUPPORT AND

SPONSORSHIP:

Nil

\section{CONFLICTS OF INTEREST:}

There are no conflicts of interest.

\section{ACNOWLEDGEMENTS:}

I warmly acknowledge my past Professor and HOD, Dr.T.Ramakrishnan who is now the Principal of Meenakshi Ammal Dental College.

\section{REFERENCES:}

1. Anderson KM, Behrents RG, McKinney T, Buschang $\mathrm{PH}$. Tooth shape preferences in an esthetics smile. Am J Orthod Dentofacial Orthop. 2005. Oct;128(4):458-65

2. Ribeiro FV, Caraveller $\mathrm{CP}$ et al.Esthetic treatment of gingival hyperpigmentation with $\mathrm{Nd}$ :YAG laser or scalpel technique: a 6-month RCT of patient and professional assessment Lasers Med Sci 2014;29:537-544

3. Tamizi M, Taheri M. Treatment of severe physiologic gingival pigmentation with free gingival autograft. Quintessence Int 1996;27:555-558

4. TalH,Landsberg.Cryosurgicaldepigmentation of the gingiva.a case report.J Clin Periodontol $1987 ; 4: 614-617$

5. Chandna SH, Kedige SD.E valuation of pain on use of electrosurgery and diode laser in the management of gingival hyperpigmentation: a comparative study.J Indian Soc Periodontol 201t5:19:49-55

6. Low SB, Mott A. Laser technology to manage periodontal disease: a valid concept? J Evid - Based Dent Prac 2014; 14(Suppl):154-158

7. Dr. Harvey A. Wigdor DDS, MS Joseph T. Walsh Jr. PhD Lasers in dentistry.Lasers in surgery and medicine 1995:16:103-133
8. Perlmutter S, Tal $\mathrm{H}$. Repigmentation of the gingiva following surgical injury. J Periodontol 1986;57:48-50. 